be "strictly private, and that the names of the writers should not be given up, nor themselves brought into trouble or diff. culty in any way." Well might Mr. Humfrey animadvert upon the use that had been made of confidential letters, written on request, and under such a pledge as had been stated. I do not cite this case because it is creditable to our profession, but to show how much confidence may be placed on the word and honour of the servants of insurance companies. If this case does not prove to the satisfaction of Widow Sutton and Sons, that sometimes, to serve an end, the pledges of the immaculate insurance companies are broken, $\bar{I}$ think it will convince the profession of the fact.

I am willing to concede that the answering of the questions put by the insurance company at the request, and with the cognizance, of a patient, may not, strictly speaking, be a breach of professional confidence; but would it not be so, in some instances, to comply with the request contained in the note which accompanies the queries, and which runs thus-" They (the company) will esteem it a favour if you will have the goodness to answer the questions printed on the other side of this letter, and to communicate, from your own knowledge, such further information respecting his constitution, health, and general manner of living, as may enable them to form an opinion on the safety of insuring his life"! For whose advantage is this information to be given? for that of the patient?no; but for that of the insurance company; for by the reply, if unfavourable, the hopes of the applicant are blighted, and the company saved from undue risk. If the above was all that a medical man was desired to answer, I contend that he has, by so doing, fairly earned his fee from the company addressing him.

In the two succeeding paragraphs of their letter, Widow Sutton and Sons are modestly pleased to express their surprise that you should let an imputation on the honour of the profession pass. In that which I wrote, there is no imputation on the honour of the profession; but they wilfully or stupidly choose to misunderstand the meaning, and express themselves shocked at the immorality, of this sentence- " If insurance companies want true answers, they should adopt some method which would not compromise the medical man with his patient; and they should pay him." Clearly this means, they should pay for information if they want it, and they should endeavour to obtain it in such a manner, that the person whom they apply to may suffer as little detriment as possible, if his answers are unfavourable to the person wishing to insure. It does not bear the meaning Widow Sutton and Sons have put on it, that unpaid-for answers would be false; but there is little doubt they might be short, and not over satisfactory; for in the medical profession, and even perhaps in the high and moral atmosphere of an insurance office, unpaidfor services to the rich would be rendered unwillingly, though to the poor our profession every day give their best services, without hope or wish for fee or reward.

The next paragraph, if I understand it, is intended to convey a covert doubt of my respectability; $I$ shall therefore pass it, as it is hardly necessary to defend that against the sneer of the agents to an insurance company. Widow Sutton and Sons then say they are willing to leave the main question on the ground taken by Mr. Stookes himself, which is, the parties seeking information for their benefit should pay for it; they agree to this, but argue that the person wishing to insure is the person benefited. I contend that the answers of the medical man benefit the company, inasmuch as if a good life is insured, they receive the profit, and if a bad one is refused, because of his answers, they are decidedly the only persons benefited by the knowledge conveyed to them by the medical man and therefore, by their own showing, should not refuse the fee.

My opponents wind up by likening the person wishing to insure, to an estate for sale, and to which he must give a good title, and argue he must pay his own lawyer. True; but that lawyer would not think himself bound to point out the flaw, if there was one, but would leave it to be discovered by his legal brother. Well, let the applicant for insurance be an estate, there will be no need to prove him freehold of inheritance, but only that the stability of the buildings, the state of cultivation, \&c. \&c., should be examined into. This the purchaser would be at liberty to do for himself, or if he wanted it done by one of more experience, he would pay him; and did he want the evidence of another authority, $I$ fancy he would pay him also. So then, in future, let medical men say, "You can look at the estate, and your man of skill can do so; but if you want our warrant of condition also, yon must pay us."

The length of this letter, I fear, will trespass on your space, but the subject is an important one, because it is of every-day occurrence, and it should be definitely settled whether medical men should or should not give certificates, for the purpose of effecting life assurances, without a fee is paid by the insurance offices. If the profession think with me that the companies should pay, let them, one and all, resist the demand, and either the insurance companies must pay what I contend is a just debt, or they must shortly shut up shop. The profession have the power in their own hands, let them resist this injustice.-I am, Sir, yours, \&c.

Newington, Liverpool, April 20, $1846 . \quad$ Aldex. STrookes.

\section{THE ETIQUETTE OF THE PROPESSION.}

WE have received a letter from Mr. Beecroft, who, in answer to Mr. Vaudrey's note in The LANCET of May 2nd, observes that, "No mention had been made of calling in another medical man, or any dissatisfaction evinced at my treatment, when I proposed to consult with Mr. Vaudrey. He first understood distinctly from me, on the Saturday, (March 14th, my fourth visit,) that the child had hydrocephalus, and that it was in danger. Mr. Vaudrey was sent for on the Tuesday following to meet me, and when he came, he (the father) was from home; but on arriving at home in the evening, Mrs. - told him that 'Mr. Vaudrey said that the child had lumbago.' Miss - - , who was present, also told me, that 'Mr. Vaudrey said that the patient had no more the water in the head than he or her mother had." Thus it appears, by the above evidence, that the "direct insult to the lady' was made by Mr. Vaudrey himself.

"It seems that Mr. Vaudrey has at last, after several weeks" consideration, arrived at the same diagnosis as myself; for I think all modern authors on the subject concur, that ' tubercular meningitis' (I presume Mr. Vaudrey means) is the most frequent cause of hydrocephalus; and as regards my medical treatment of the case, probably Mr. Vaudrey received more benefit from my explaining to him the treatment I was pursuing than he will acknowledge."

Mr. Beecroft then advocates the employment of purgatives in hydrocephalus, and gives his reasons for not ordering into a secluded apartment the patient, in the case alluded to by Mr. Vaudrey at page 506; but as this case has apparently little to do with the main point in discussion, we need not here enter into further details respecting it.

\section{THE MEDALS OF THE ROYAL SOCIETY.}

(LETTER FROM MR. NEWPORT.)

To the Editor of Th LanceT.

Sir,-I am not aware that I have given to you, or to any other person, just cause to assert that I am disposed " to cavil," or be "always accusing." My letters to your journal have been wrung from me, much against my inclination, by repeated unjust attacks in your leading articles, and $I$ have much regretted to find that the writer of those articles, whoever he may be, instead of receiving my statements with that impartiality, candour, and courtesy which I had hoped was their due, has met them with flat and positive denial, on "authority," and that, too, in the very face of the reference $I$ gave to Dr. Hall's own words, in page 749 of your own journal, for February 17th, 1838 .

The statements which I made were, that Dr. Hall sent a letter of mine, dated July 23, 1832, to the Council of the Royal Society in November, 1836; and that, for reasons I have already given, I regarded the very act of sending that lettex as " misrepresentation."

The writer of your leading articles has denied the truthfulness of my asserted fact, and has repudiated the justness of my appreciation.

But Dr. Marshall Hall's own printed words, at the page I have referred to, establish the truth of my assertion, and the justness of my conclusion. Dr. Hall there expressly states, that on seeing the note in my paper, "On the Temperature of Insects," he immediately addressed the Council of the Royal Society, and after quoting the note at length, he adds, -

"I beg to state, in reply, that on the 'recent occasion' alluded to, a letter addressed by Mr. Newport to me, and containing the following paragraph, (see The Lancet, April 25th, 1846, page 470 ,) was forwarded by me, (these four words are actually printed in italics,) through the medium of a Fellow of the Royal Society and a member of the Council."

Dr. Hall then quotes the paragraph from my letter, and further remarks, -

"It will be obvious and palpable to every one, that the fact of my having sent that letter renders that of my having made the 'misrepresentation' insinuated impossible." 
$I$ have already stated that $I$ regard the very act of sending that letter as "the misrepresentation."

These printed statements, by 1)r. Mall, in Tre Lancer of February 17th, 1838, excepting only the two words, "in reply," are verbatim copies of portions of his own autograph letter, addressed "To the Conncil of the Rioyal Society," and which, fortunately for me, is in the care of the assistant secretary of the Royal society, and may be inspected by any of the Fellows, on application to that oficer.

It will now be seen that the "authority" on which the writer of your leading articles has relied, in denying my facts, is utterly unworthy of credit; and never again can it be questioned that my letter to Dr. Hall was sent by Dr. Hall himself to the Council of the Royal Society in November, 1836, and also a paragraph of it (copied) in February, 1838.

This exposition of facts, more detailed than that which $I$ had already given, together with the new accusationg of "thrusting cavilling upon your readers," and of "always accusing," must entirely preclude me from entering into any further discussion in your journal.

No charges, made or threatened, of "low estimate," of " cowardice," of " inuendo," of " cavilling," or of "always accusing," shall again extort from me a reply, in return for which, to judge from the past, I might expect only further aspersion; nor shall any fear of injury make me shriak from the declaration, when $I$ see fit, of what I know to be correct and just.

$I$ will conclude these, the last remarks $I$ intend to address to you, with your own words-" In all the common affairs of life there is the right of appeal against injustice. In science, there is no appeal, save to time and to posterity."

Your obedient servant,

Upper Southwick-street, Cambridge-terrace, GEOBGE NewPort. May, 1846.

THE MEDALS OF THE ROYAL SOCIETY.-DR.LEE'S DEMONSTRATIONS OF THE UTERINE NERVES. (LETTER FROM DR. TODD.)

To the Editor of The Lancet.

SiR,-After the exhibition of personal feeling which the last few weeks have witnessed, in connexion with the controversy respecting the nerves of the uterus, I am scarcely surprised at the extraordinary misconceptions which have been put forth by some one or other regarding my own opinions on this anatomical point.

In a late number of the Literary Gazette, I was shown the following paragraph:- "Dr. Todd now admits that Mr. Beck's dissections confirm those of Dr. Lee ;" and in your last week's number of The LANCET, you relate, "on authority," an incident which you say occurred on a recent occasion, when, on Dr. Lee's invitation, in his own house, and in company only with Dr. Lee, and my friend Mr. Simon, I was shown the Doctor's preparations.

I have already written to the editor of the Literary Gazette, to give the most unqualified contradiction to the paragraph which appeared in that journal.

With respect to the statement in The LANCET, so far as it asserts that I made any admission in favour of Dr. Lee's pecu. liar views, it is altogether in error; and the charge against me, of not knowing a great nerve "known to Galen," affects me so little, that I do not think it worthy of contradiction.

$$
\text { I am, Sir, your obedient servant, }
$$

New-street, Spring-gardens, May, 1846.

R. B. ToDd.

[We would tell Dr. Todd that no "personal feeling" has influenced us in what has transpired relative to the Royal Society. Dr. Todd might very appropriately have held a higher view of the matter than this. Personal injustice is bad enough, but it is not persons, so much as the sciences of anatomy. and physiology, which have been wounded by the transactions in which he has borne so prominent a part; and certainly his dignity is not so pre-eminent, but that he might stoop to contradict the assertion that he did not know the hypogastric nerve when it was shown to him-if the assertion could, indeed, with truth, be contradicted?-ED. L.]

THE MEETING OF THE NATIONAL ASSOCIATION. (NOTE FROM Mr. DAVIS, OF HAMPSTEAD.)

To the Editor of THE LANCET.

Srr,- $\mathrm{I}$ think it a duty $\mathrm{I}$ owe the medical public, as well as myself, to correct your report of April 25 , of what $Y$ said at the meeting of the National Association of General Practi- tioners in Medicine, Surgery, and Midwifery, held at the Hanover-Square Rooms. It may be immaterial what $I$ did say, but not so that which I did not say, being calculated to mislead. My friend, Mr. Downing, was a staff-surgeon, and refused to do medical duty; therefore I attended 210 (not one) patients for him, to prevent a court-martial. It was of surgeons only I spoke, and not of physicians. They never' wronged me, or other old members of the College of Surgeons. We never were physicians. But if we had run their prescribed curriculum, and become fellows or licentiates of their body, as we did that of surgeons, and become members thereof, we should have been protected in our " rights, privileges, and immunities." They would have rendered unto Cœsar the things which were Casar's; and no minister of state, or wily surgeon " extraordinary," with the same diploma as ourselves, could have robbed us of our title to equal rank by an ex post facto law; but any new thing, misnamed a charter, would have honestly run thus-" From and after the date hereof, be it enacted," \&c. \&c., securing equal rank to those in possession, with the exception only of those who had rendered themselves unworthy of it. Verbum sat sapienti. Although it may be unimportant to those of my age and standing in the profession, what is done or left undone by the " powers that be," perhaps you may insert this, and oblige, your obedient servant,

Hampstead, May, 1816 .

Thomas Davis.

\section{NON-QUALIFIED VISITING ASSISTANTS.}

\section{To the Editor of THE LANCET.}

Srr,-As I wish you every success in your crusade against quackery, I trust you will kindly excuse my directing your attention to the most grievous intra-professional nuisance of this description in existence. To the best of my knowledge, it has not even been hinted at by any journal, hitherto, and the only reason I can give for the oversight is, that nine out of ten medical practitioners are daily countenancing the fraud. I allude to the employment of non-qualified visiting assistants.

A medical man, perhaps already in good private practice, is appointed surgeon to an Union at 100l. per annum, or any other sum he may engage to attend the poor for. He knows he cannot attend to his private patients and Union patients likewise; he therefore hires an assistant, who, for $25 l$. or $30 l$. a year, visits and prescribes for nine-tenths of the paupers, and, moreover, attends midwifery cases, although he may never have even seen a human uterus, much less have studied the minute and relative anatomy of the organ.

The poor people have no alternative; the Union surgeon must be employed, and other private practitioners are shut out from this source of information, unless they attend gratuitously. In this manner is the profession stocked with quacks, by the profession; your bonesetters, midwives, et hoc genus omne, may frequently be traced to this source. If a man can, without the qualification that appears to be so much insisted upon, visit and prescribe for one hundred paupers, why may he not do the same for a hundred noblemen or squires? $\quad$ Yours, \&c. Scalpex.

\section{THE WATERS OF VERNET, (PYRENEES,}

AND THE MODE OF THEIR APPLICATION IN THE TREATMENT OF DISEASE.

Is an establishment at Vernet, the waters from hot sulphurous springs are conveyed through open pipes, so as to maintain the temperature constantly at sixty degrees. A correspondent states, that both the equable temperature and the medicated atmosphere have been fornd beneficial to phthisical patients. His remarks on this subject are,-

"Every one knows that the hydro-sulphuric waters are most useful in all chronic affections of the lungs. The reputation of the Eaux Bonnes (Pyrenees) in all cases of this kind is very well known. But how are these waters generally employed? In baths-or they are more usually drunk. The waters of the Eaux Bonnes can only be administered in these modes, on account of their low temperature. If sulphurous waters are found so useful in all cases of chronic pulmonary affections, applied only to the skin, or introduced into the digestive tube, how efficacious ought they not to be when they are brought into immediate contact with the very organs affected-when, in a word, they penetrate into the remotest ramifications of the air-vessels. All medical practitioners have acknowledged the importance of immediate direct action, and very many of them have imagined ways in which pulmonary patients may be enabled to breathe a medicated air. In order 